
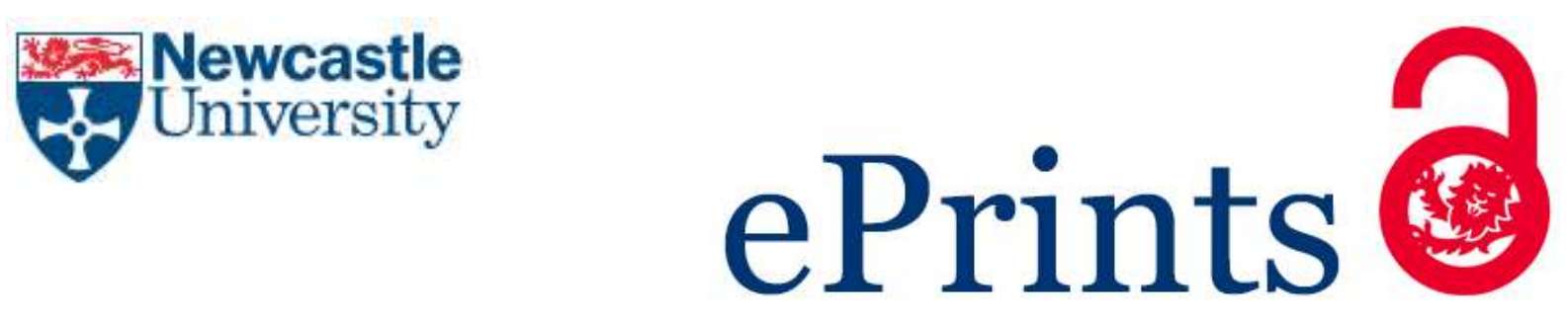

Armstrong R, Ferracina S, Caldwell G, leropoulos I, Rimbu G, Adamatzky A, Phillips N, De Lucrezia D, Imhof B, Hanczyc MM, Nogales J, Garcia J. Living Architecture (LIAR): Metabolically engineered building units. In: Heisel, F; Hebel, D, ed. Cultivated Building Materials: Industrialized Natural Resources for Architecture and Construction. Berlin, Germany: Birkhauser, 2017, pp.170177.

\title{
Copyright:
}

This is the authors' accepted manuscript of an article that has been published in its final definitive form by Birkhauser, 2017

DOI link to article:

https://www.degruyter.com/view/product/473454

Date deposited:

$16 / 05 / 2017$

Embargo release date:

01 June 2018

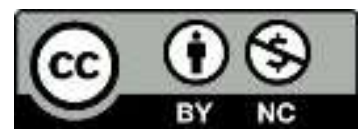

This work is licensed under a Creative Commons Attribution-NonCommercial 3.0 Unported License 


\section{Living Architecture (LIAR): Metabolically Engineered Building Units ${ }^{1}$}

Rachel Armstrong, Andrew Adamatzky, Anil Wipat, Gary S. Caldwell, Simone Ferracina, loannis leropoulos, Iwona Gajda, José Luis García, Juan Nogales, Barbara Imhof, Davide de Lucrezia, Neil Phillips, and Martin M Hanczyc

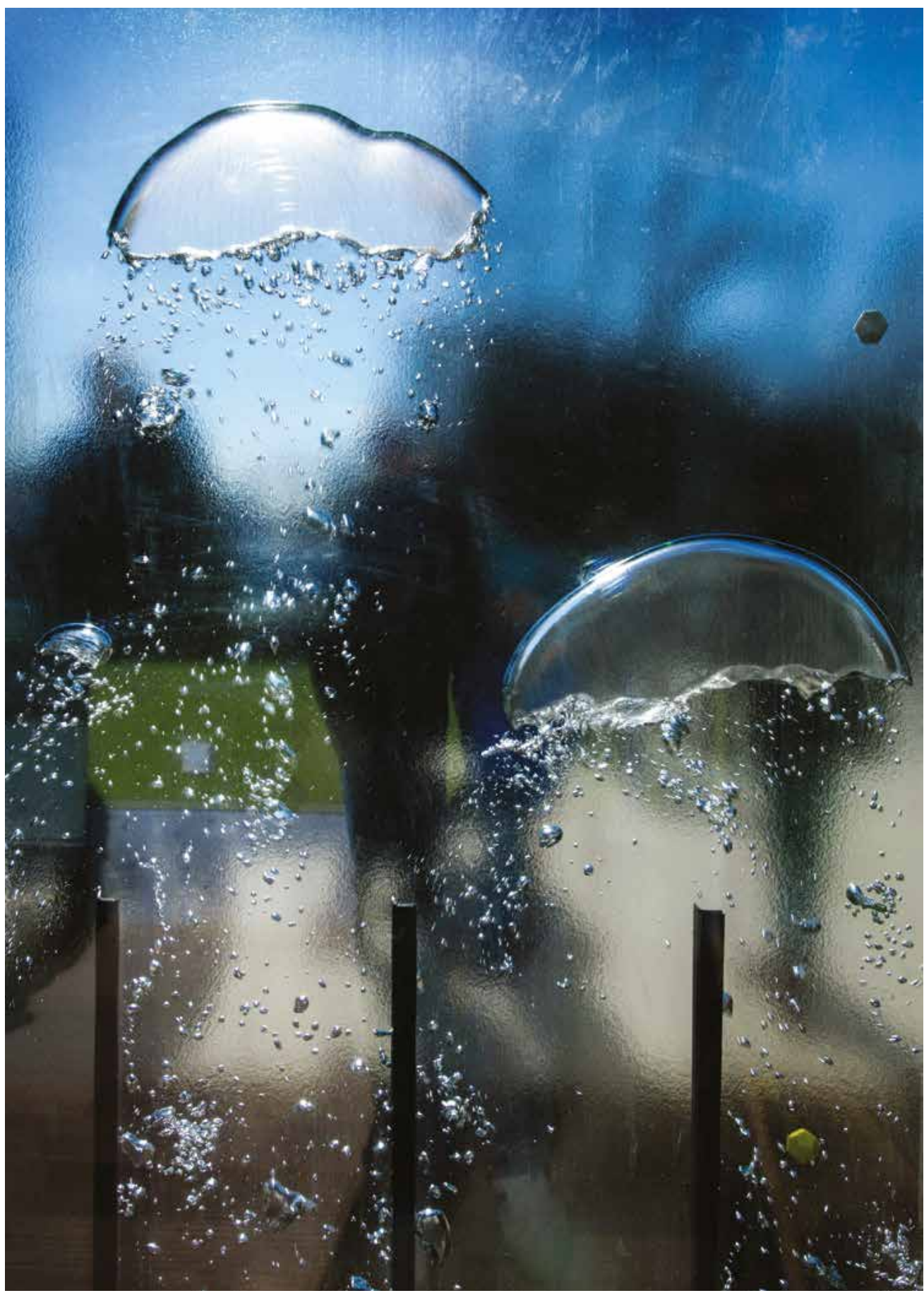

- Bioreaction within Arup's state-ofthe-art BIQ (Intelligent Building) House in Hamburg, 2013. The algae serve as a form of micro-agriculture. 


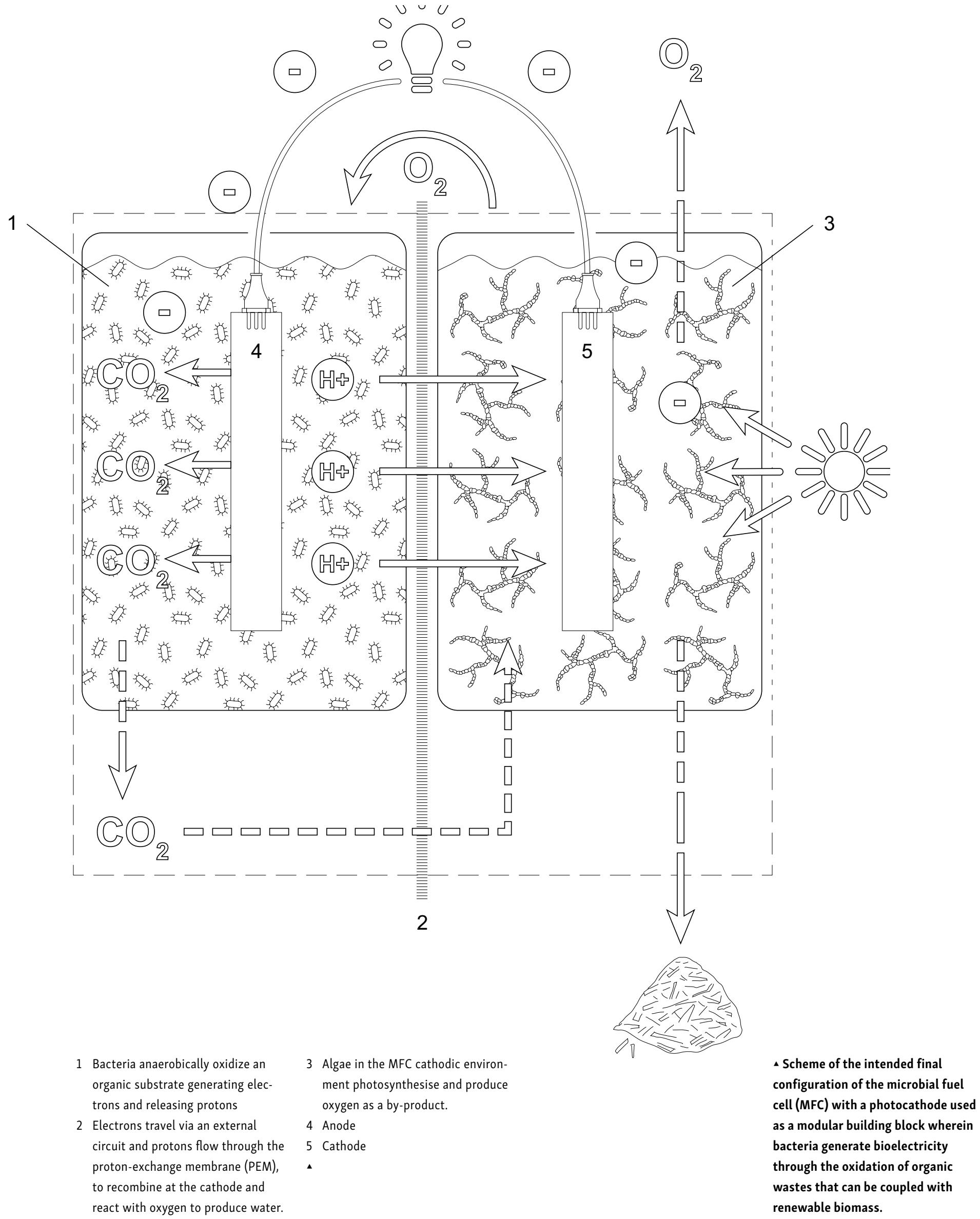




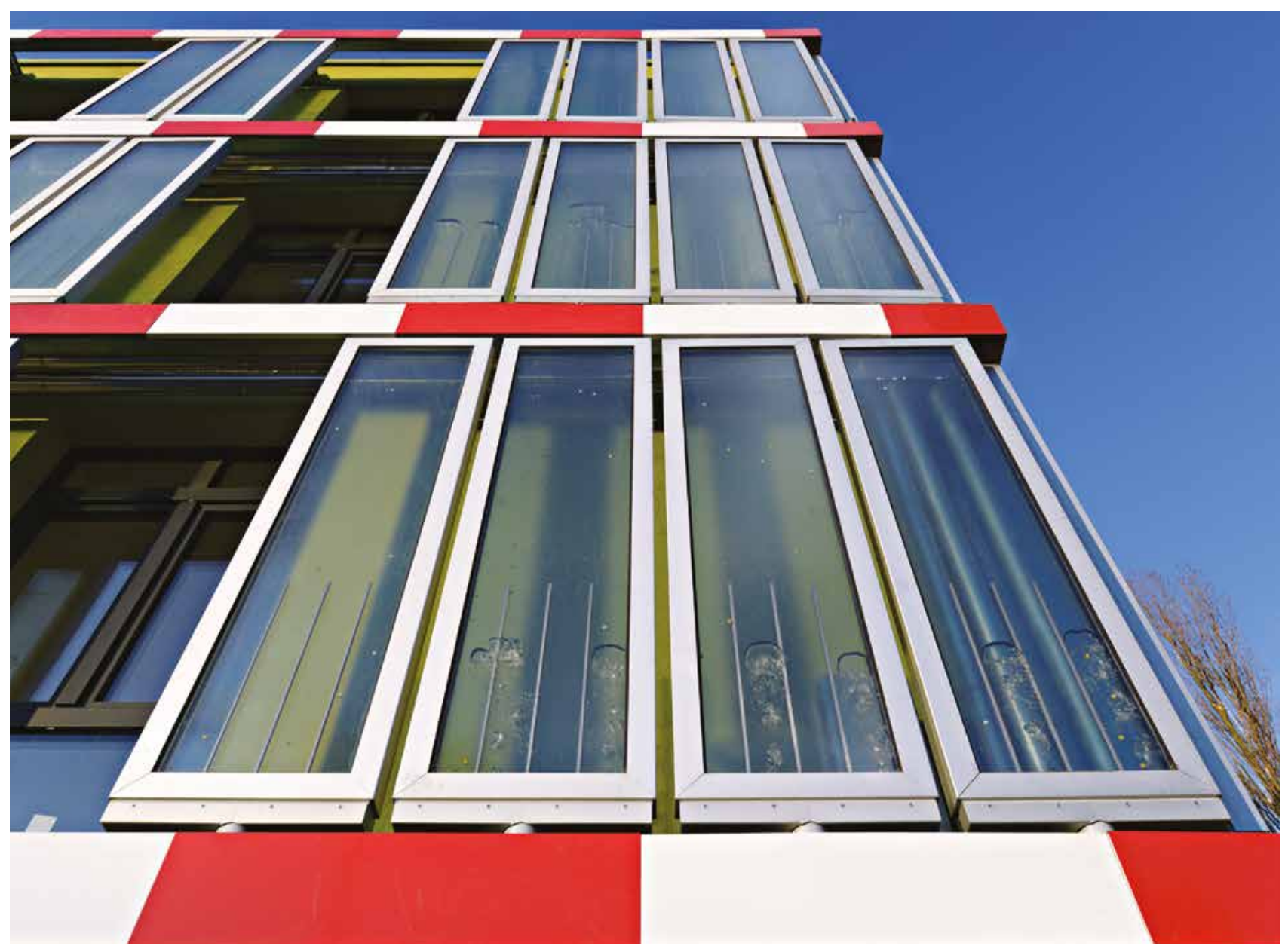

Buildings are often described in terms that infer they possess "life". Architectural design, in the same spirit, frequently explores ideas about the living world, the body and nature - through various approaches to the construction and choreography of space. Yet, most buildings are constructed according to industrial paradigms based on inert materials, or materials that were formerly, but are no longer, "lively" such as wood, bricks, and soils, materials that are processed into inert forms obedient to top-down design processes.

We are currently entering an ecological era in which we are increasingly viewing reality as a hyper-complex and interconnected, open system with constant fluxes of energy, matter, and information.
This shift has become an everyday reality with, for example, the advent of the Internet, which has allowed us to transgress previously irreducible divides of geography, culture, politics, matter, and identity. Yet the ecological era does not concern the greening of things, or simply substituting an object-centred view of reality with a process-oriented one. Rather, it requires us to develop technical systems that speak to the principles of design and engineering with living systems. The innate properties of lifelike systems exceed the expectations of traditional approaches of construction and invite the development of an ecological approach to architectural practice that invokes the cultivation of building materials. This approach is predicated on the dynamic adaptability and variation
- Façade detail of the BIQ House. Energy savings were made within the building through the solar-thermal effect of algae biomass. 


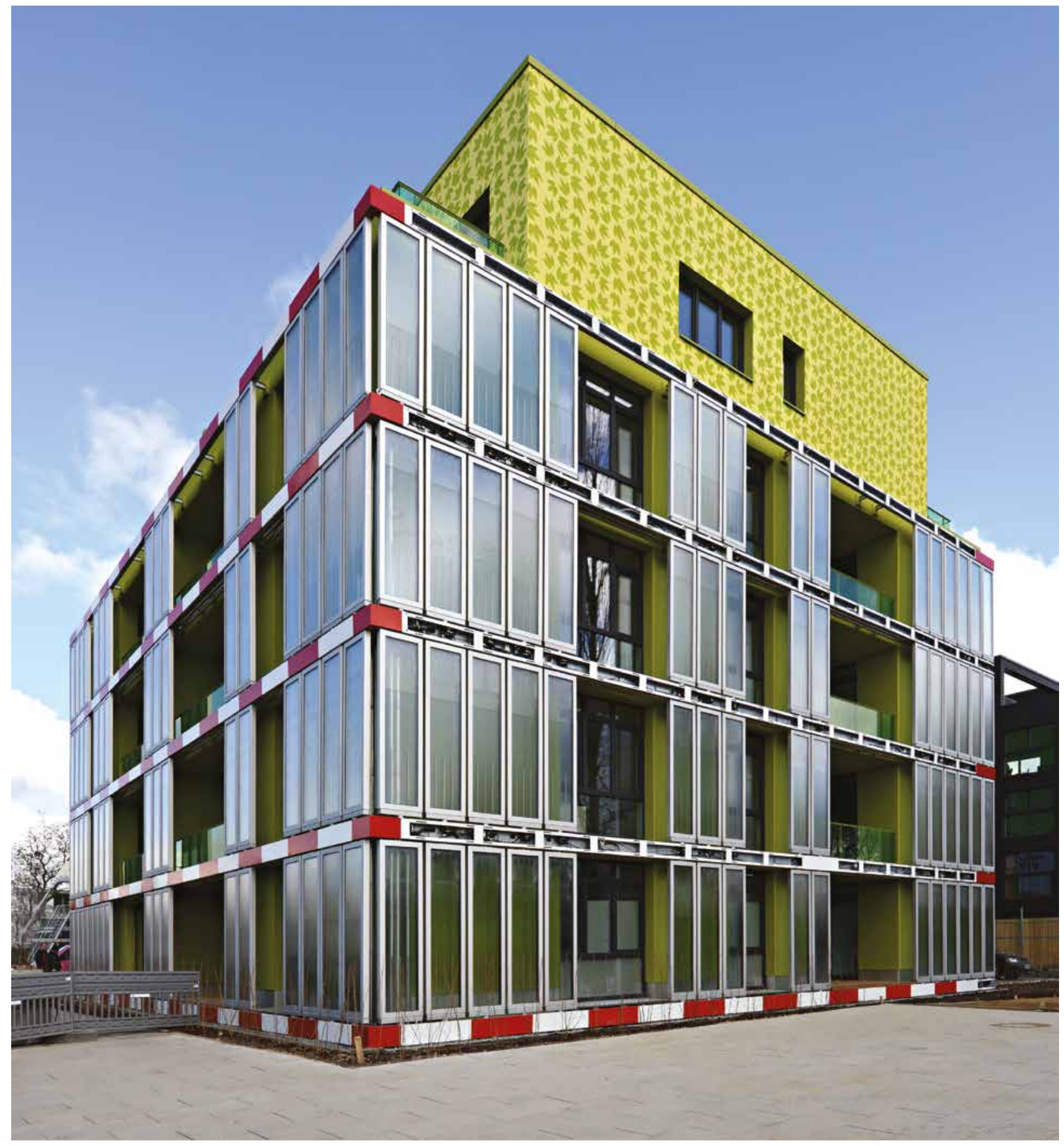

- The BIQ House grows and harvests algae biomass that reduces both energy demand and $\mathrm{CO}_{2}$ emissions compared to a common building system. It was part of the International Building Exhibition in Hamburg, 2007-2013. 


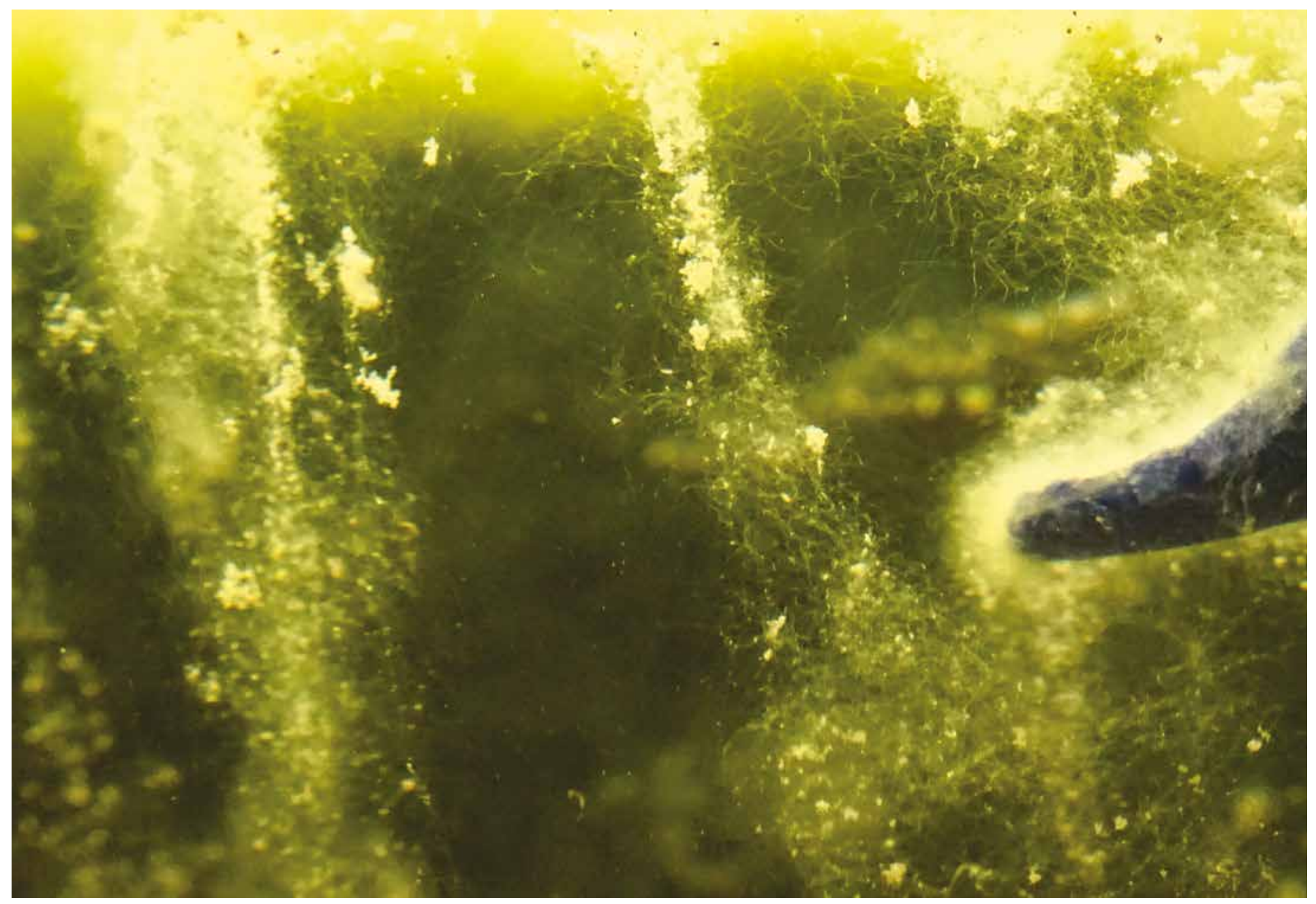

implicit in living systems, and it shifts away from the traditional view of architecture as a static, form-giving subject that is centred on making a building, but rather moves towards developing alternative ways of choreographing matter in relation to populations and sites.

\section{Life's systems as technological intervention}

In an age of biotechnology, new ideas, materials, and technologies enable us to consider life itself as a technology and to not only manipulate life's fabrics, but also use life's systems themselves as the technical intervention. Transposing the technical competencies of biological systems from the nano-microscale to the architectural-human scale is challenging. The issues of scale can be addressed, in an architectural context, by seeking technological convergence and coordinating metabolic materials or agents in space.

In 2013, the international engineering company Arup built the first publicly accessible algae façade for the BIQ House in Hamburg, Germany, which served as a form of micro-agriculture. In addition, energy savings were made within the building through the solar-thermal effect of the algae biomass. ${ }^{2}$ More recently, the Senseable City Laboratory at the Massachusetts Institute of Technology in Cambridge, Massachusetts, and the ecoLogicStudio in London produced an algaeponics design for the 2015 Milan Expo. ${ }^{3}$ These architectures function as cellular gardens that are farmed, but do not engage $\triangle$ Algae biomass represents the idea of a living architecture. 


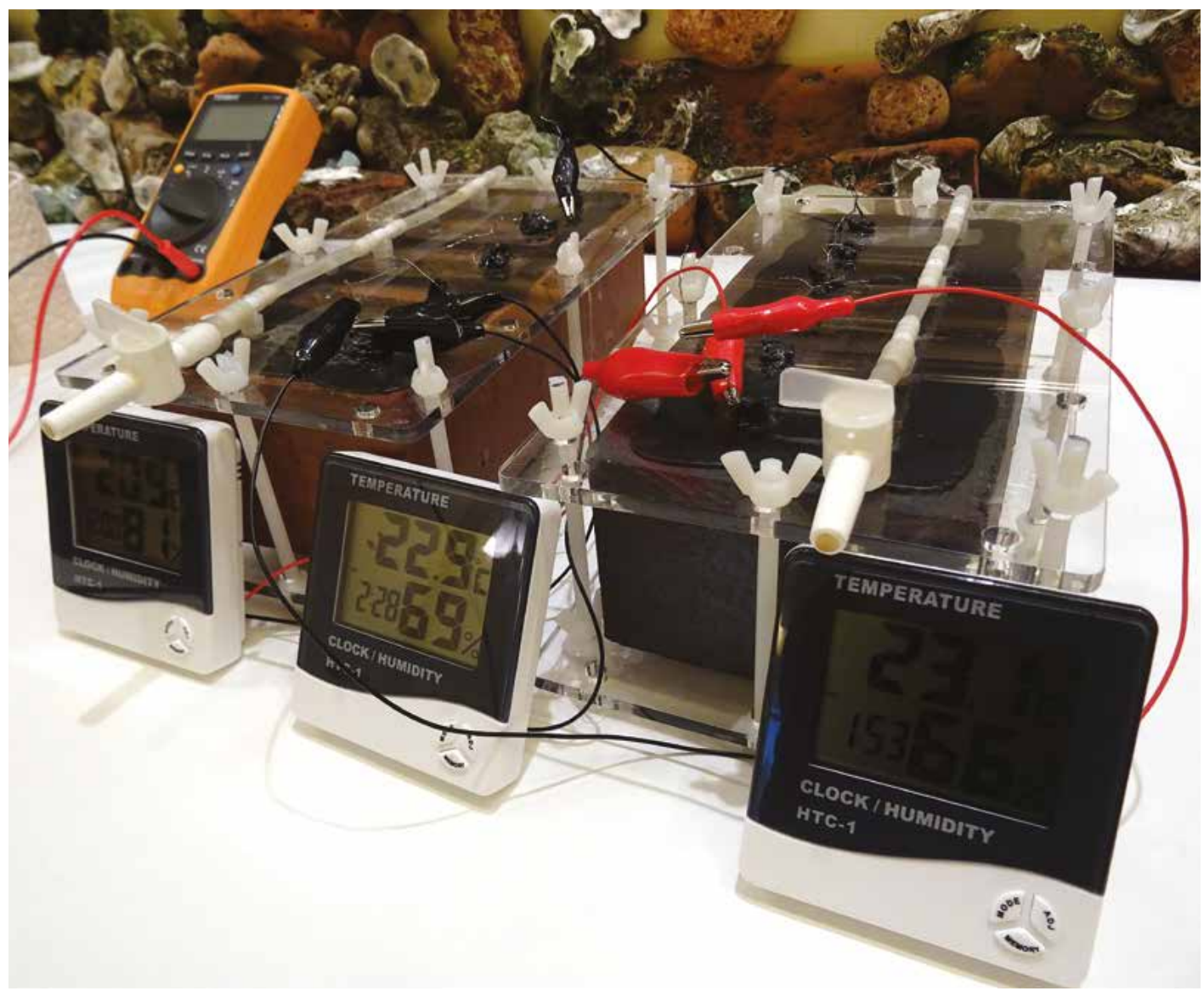

with the principles of directly designing with life. Even so, such concepts are of interest and widely entertained in architectural design from Terraform One's In Vitro Meat Habitat, which proposes to culture an entire building from laboratory-grown pig cells, ${ }^{4}$ to bioluminescent trees created with the help of genes (GFP - Green Fluorescent Protein) originally from bioluminescent jellyfish, proposing to supply off-grid, low-level lighting in the Genetic Barcelona Project of the Genetic Architectures Research Group at the Universidad Internacional de Cataluña. $^{5}$

\section{Beyond biomimicry}

Biomimicry proposes to copy or be inspired by nature to produce more efficient solutions. ${ }^{6} \mathrm{Be}$ - yond biomimicry, a field entitled biomimetics aims to not only be inspired by nature, but translate biological principles into mechanisms, technologies, or other technical systems. It remains the question whether there is even a step beyond biomimicry? An answer could arise from the staggering advances of the past decade in the life sciences, particularly in metabolic engineering, where "the realm of the born - all that is nature - and the realm of the made - all that is humanly constructed - are becoming one". P Potentially, these synergies could be harnessed heralding a new age in the design and engineering of living things. ${ }^{8}$ It is this disruptive vision that the Living Architecture (LIAR) concept seeks to explore. ${ }^{9}$ LIAR integrates a suite of established (algaeponics, microbial fuel cells,
- The microbial fuel cell (MFC) in operation, as exhibited at the Biennale, $15^{\text {th }}$ International Architecture Exhibition, in Venice in 2016. 
unconventional computing, and robotics) and yetto-be-established technologies and processes to produce a unique modular computational metabolism construct, a construct that is to illustrate the scope for next-generation living systems at an architectural scale.

\section{Living Architecture (LIAR) for the built environment}

Living Architecture (LIAR) is conceived to produce standardized components (architectural, robotic, metabolic, and control software) as an operational unit of construction for an ecological era. Cultivated building materials offer potentials to adapt the living environment to meet the needs and desires of the occupants. Such a kind of functional architecture has not yet been built, but a consideration of its technical feasibility begins to outline some of the challenges. We anticipate such a structure to take the shape of bioreactor walls that can be installed in open environments within modern buildings. LIAR is based on the operational principles of microbial communities activating both microbial fuel cells (MFCs) and photo bioreactors as new environments.

These biological components are metabolically engineered to deliver specified biochemical and systematic functions. LIAR is conceived to become an integral component of human dwellings capable of extracting valuable resources from light, wastewater, and flue gas/exhaust air. It is to polish wastewater, generate oxygen, and produce useable biomass, fertilizer, and electrical power. As a self-learning, self-governing system it will adapt to local conditions, thereby maintaining high system efficiencies by selectively manipulating consortia performance.

A freestanding partition is conceived as a LIAR prototype, consisting of modular bioreactor units designed for incorporation into modern spaces with traditional utilities. To this purpose, the peripheral physical dimensions of the bioreactors have been defined as multiples of standard building blocks (e.g. bricks or concrete blocks). This will allow them to be effectively nested within walls if not left on display in open spaces, while maintaining both structural integrity and providing thermal mass. In the longer term, LIAR is aimed at applications within the built environment to address global-scale challenges relevant to urban sustainability, resource management, and the circular economy. ${ }^{10}$

\section{Impacts}

The current model proposed for LIAR has potential commercial relevance in the development of home appliances, e.g. washing machine technology and water purifiers for kitchens and bathrooms. In this way, living spaces are to become programmable ecosystem modules that can be customized to suit the resources and needs of a community. Commercially speaking, LIAR would not compete with industrial-scale operations of production, but aims to add value to the health of environments, recycling scarce resources and supporting products with reusable or tradable value.

LIAR has the potential for far-reaching and transferable impacts on the performance of our living spaces and cities. It implies a new understanding of sustainability ${ }^{11}$ that goes beyond resource conserva- 
tion and incorporates the metabolic design of living spaces. Achieving this conceptual and technical breakthrough may endow our cities with robustness and resilience to the impacts of climate change while enabling inhabitants to live humanely and even profitably in the highly resource-constrained and competitive circumstances of the future.

\section{ENDNOTES}

1 The project has received funding from the European Union's Horizon 2020 Research and Innovation Programme under Grant Agreement no. 686585 .

2 Steadman, I. (2013), "Hamburg unveils world's first algae-powered building", Wired [website], http:// www.wired.com/design/2013/04/ algae-powered-building/, last accessed on 14 July 2015.

3 Medina, S. (2014), EcoLogicStudio, Metropolis Magazine [website], http://www.metropolismag.com/ October-2014/EcoLogic-Studio/., last accessed 14 July 2015.
4 Armstrong, R. and Spiller, N. (2011), "Synthetic biology: Living quarters", Nature 467, 916-918.

5 Myers, W. and Antonelli, P. (2013), Bio Design: Nature, Science, Creativity. London: Thames \& Hudson/New York: MOMA, 68-69.

6 Beynus, J. (1997), Biomimicry: Innovation inspired by Nature. New York: William Morrow.

7 Kelly, K. (1994), Out of Control: The Rise of Neo-Biological Civilization. Boston: Addison-Wesley, 1994.

8 Venter, J. Craig (2013). Life at the speed of light: From the Double Helix to the Dawn of Digital Life. London: Little, Brown.
9 Living Architecture (2016) (website), http://livingarchitecture-h2020.eu, last accessed 9 July 2016.

10 Ellen MacArthur Foundation (no date), Circular Economy (website), http://www.ellenmacarthurfoundation.org, last accessed 29 October 2015.

11 World Commission on Environment and Development (1987), Our Common Future. Report of the World Commission on Environment and Development, published as Annex to General Assembly document A/42/427, http://www.un-documents.net/our-common-future.pdf, last accessed 14 July 2015. 